\title{
Extraction Studies of Heavy Metal Ions Employing Benzothiaoxacrown Compounds
}

\author{
Tsermaa TSEND-AYUSH ${ }^{1}$, Marco WENZEL ${ }^{1}$, Kerstin GLOE$^{1}$, Karsten GLOE ${ }^{1}$, Jan J. WEIGAND ${ }^{1}$, \\ Yuri V. FEDOROV ${ }^{2}$, Olga A. FEDOROVA ${ }^{2}$, Sergey P. GROMOV ${ }^{2}$ and Paul G. PLIEGER ${ }^{3}$
}

1. Department of Chemistry and Food Chemistry, TU Dresden, 01062 Dresden, Germany

2. A. N. Nesmeyanov Institute of Organoelement Compounds, Russian Academy of Sciences, Vavilova Str. 28, 119991 Moscow, Russia

3. Institute of Fundamental Sciences, Massey University, Palmerston North 4442, New Zealand

(Received May 9, 2015; Accepted August 21, 2015)

Benzothiaoxacrown compounds with different numbers of sulfur and oxygen donor atoms (between 4 to 7 donors) dissolved in an organic diluent selectively extract the soft metal ions $\mathrm{Ag}$ (I) and $\mathrm{Hg}$ (II) from a mixture of $\mathrm{Co}(\mathrm{II}), \mathrm{Ni}(\mathrm{II}), \mathrm{Cu}(\mathrm{II}), \mathrm{Zn}(\mathrm{II}), \mathrm{Ag}(\mathrm{I})$ and $\mathrm{Hg}(\mathrm{II})$ present in an aqueous phase. Generally, the extraction efficiency depends on the specific structure of the benzothiaoxacrowns, on the organic diluent employed, as well as on the counter ion present in the aqueous phase. High extractions of $\mathrm{Ag}$ (I) and $\mathrm{Hg}$ (II) were achieved with all ligands from perchlorate and picrate aqueous media into nitrobenzene organic solutions. In the case of $\mathrm{Cu}(\mathrm{I})$ the extraction is significant lower; only ligand 5 with the $\mathrm{O}_{2} \mathrm{~S}_{4}$ donor atom set gives a moderate extractability. The composition of the extracted complexes depends on the crown ring size and ranges from 1:1 to 1:2 (M:L). Polarographic, UV-Vis and ESI mass spectrometric studies provide a further insight into the complex formation behavior.

\section{Introduction}

The separation of toxic and valuable heavy metals from process solutions or waste water is of great importance for both the recovery of such metals and the protection of the environment. Solvent extraction is a very efficient separation process for metal ions in solution and is widely used in industry [1,2]. The success of the separation strongly depends on the individual properties of the employed extractant. Although many different extractants are known and a number have been commercialised, there is still a further need to search for more selective reagents [3]. In this context, macrocyclic crown compounds with $\mathrm{N}, \mathrm{O}, \mathrm{S}$-donor functions are an interesting class of compounds with different options to control their selectivity towards metal ions [4,5]. Generally, the strong affinity of thiacrowns especially for $\mathrm{Cu}(\mathrm{I}), \mathrm{Ag}(\mathrm{I})$, $\mathrm{Hg}(\mathrm{II})$ and $\mathrm{Pd}(\mathrm{II})$ is well-known and was tested for different practical purposes [6-17].

Over the years we have been involved in the design, synthesis and testing of novel thiacrown and structure-related open-chain extractants [18-21]. In several papers we have discussed the extraction properties and structure-extractability relationships of different benzothiaoxacrown compounds towards soft metal ions like $\mathrm{Ag}(\mathrm{I})$ and $\mathrm{Hg}(\mathrm{II})$ [22-24]. We have also reported the synthesis routes [25-27] and some structural data [28-30] for the benzothiaoxacrown compounds 1-6 (Scheme 1) studied in the present paper. This series of benzothiaoxacrown compounds, varying in both the macrocyclic ring size and the 
combination of $\mathrm{O}$ and $\mathrm{S}$ donor atoms,

Scheme 1.

were investigated in single and competitive metal ion liquid-liquid extraction experiments. For comparison, the benzothiazolium substituted benzothiaoxacrowns 7 and 8 (Scheme 1) were included. Furthermore complementary polarographic, UV-Vis and ESI-MS spectrometric measurements have been undertaken in

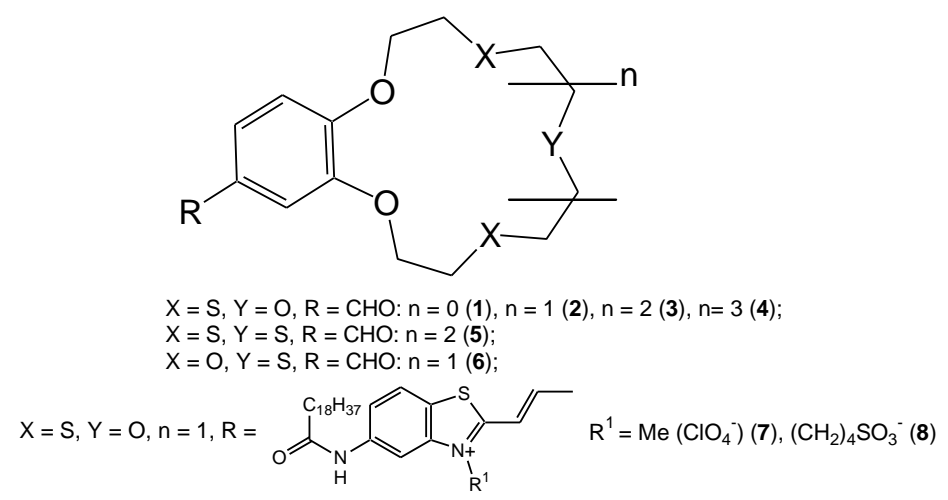
order to obtain additional information on the complex formation process involved.

\section{Experimental}

The benzothiaoxacrown compounds were prepared as described previously [25-27]. All the chemicals used were of analytical grade.

\subsection{Liquid-liquid extraction}

The liquid-liquid extraction experiments were performed at $22 \pm 1{ }^{\circ} \mathrm{C}$ in micro centrifuge tubes $(2 \mathrm{~mL})$ by means of mechanical shaking for $30 \mathrm{~min}$. The phase ratio $\mathrm{V}_{(\mathrm{w})}: \mathrm{V}_{(\mathrm{org})}$ was $1: 1(0.5 \mathrm{~mL}$ each). Chloroform, 1,2-dichloroethane and nitrobenzene were used as diluents.

The concentration of the ligands in the organic phase was $5 \times 10^{-4}-5 \times 10^{-3} \mathrm{M}$; the metal salt concentration in the aqueous phase was $1 \times 10^{-4}-5 \times 10^{-4} \mathrm{M}$. Furthermore, the aqueous phase contained picric, perchloric or nitric acid at a concentration of $5 \times 10^{-3} \mathrm{M}$. All samples were centrifuged after the extraction. The metal concentration in single metal ion experiments was determined radiometrically in both phases [31] by employing the $\gamma$-radiation of ${ }^{110 \mathrm{~m}} \mathrm{Ag},{ }^{64} \mathrm{Cu}$, and ${ }^{203} \mathrm{Hg}$ using a $\mathrm{NaI}(\mathrm{Tl})$ scintillation counter Cobra(II) (Canberra Packard).

In competitive metal ion extraction experiments and, in the case of $\mathrm{Hg}$ (II) extraction from perchlorate solution, the metal concentration was measured only in the aqueous phase using ICP-MS (ELAN 5000/Perkin-Elmer). Nitric acid (1\%) and potassium dichromate $(0.5 \%)$ solutions were added to stabilize the aqueous phase. Samples were diluted before measurement by a factor of 1:1000.

The percentage extraction E (\%) was calculated from the experimentally determined distribution ratio $D_{M}$ :

$$
\begin{aligned}
& D_{M}=c_{M(o r g)} / c_{M(w)} \\
& E[\%]=100 \cdot D_{M} /\left(D_{M}+1\right)
\end{aligned}
$$

\subsection{ESI-MS measurements}

Solutions containing 2-6 $(0.5 \mathrm{~mL}, 5 \mathrm{mM})$ in chloroform were mixed with $\mathrm{CF}_{3} \mathrm{SO}_{3} \mathrm{Ag}$ in acetone $(0.5 \mathrm{~mL}, 5 \mathrm{mM})$. In the case of ligand 1 , a ratio of $1: 2(\mathrm{Ag}(\mathrm{I}): \mathrm{L})$ was employed due to the fact that both 1:1 as well as 1:2 (M:L) complex species were observed in preliminary extraction experiments. An aliquot of each sample $(100 \mu \mathrm{L})$ was diluted with ammonium acetate solution $(1 \mathrm{~mL}, 0.1 \%)$ in methanol in order to 
promote ionization prior to the measurement. For the mass determination ESI-MS (Esquire-LC/PerkinElmer) has been used.

\subsection{UV-Vis measurements}

Aliquots $(0.3 \mathrm{~mL})$ from the aqueous and organic phases of $\mathrm{Ag}(\mathrm{I})$ extraction with $\mathbf{2}, \mathbf{3}$ or $\mathbf{5}$ were diluted with $2.7 \mathrm{~mL}$ water or $2.7 \mathrm{~mL}$ 1,2-dichloroethane, respectively. These solutions have been used for UV-Vis measurements with a Perkin-Elmer Lambda 2 spectrometer.

\subsection{Stability constant determinations}

The stability constants were determined polarographically in acetonitrile at $20^{\circ} \mathrm{C}$ using a $263 \mathrm{~A}$ potentiostat/galvanostat with a 302A Static Mercury Drop Electrode (Princeton Applied Research) as described previously [27]. The potential scanning rate was $2 \mathrm{mV} / \mathrm{s}$ and the dropping time was $1 \mathrm{~s}$. The supporting electrolyte was $0.01 \mathrm{M} \mathrm{Et}_{4} \mathrm{NClO}_{4}$.

\section{Results and Discussion}

The extraction capabilities of the benzothiaoxacrown compounds were investigated for a range of d-block metal ions, different counter ions and diluents. Figure 1 gives an overview of the extraction properties of ligands $\mathbf{2}, \mathbf{7}$ and $\mathbf{8}$ having the same $\mathrm{S}_{2} \mathrm{O}_{3}$ benzothiaoxocrown donor set towards $\mathrm{Co}$ (II), $\mathrm{Ni}(\mathrm{II})$, $\mathrm{Cu}(\mathrm{II}), \mathrm{Zn}(\mathrm{II}), \mathrm{Hg}(\mathrm{II})$ and $\mathrm{Ag}(\mathrm{I})$. The results are based on competitive extraction experiments employing a mix of these metals and using a metal perchlorate- $\mathrm{HClO}_{4}-\mathrm{H}_{2} \mathrm{O} /$ ligand-nitrobenzene extraction protocol.

As expected, the thiophilic soft metal ions $\mathrm{Ag}$ (I) and $\mathrm{Hg}$ (II) show a high degree of extraction with the benzothiaoxacrowns. Whereas $\operatorname{Ag}(\mathrm{I})$ is quantitatively extracted with all three ligands, a graded extraction in the order $\mathbf{2}(41 \%)<\mathbf{7}(91 \%)<\mathbf{8}(97 \%)$ has been observed for $\mathrm{Hg}(\mathrm{II})$. The differences between $\mathbf{2}, \mathbf{7}$ and $\mathbf{8}$ are most likely caused by the higher lipophilicity of the benzothiazolium substituted ligands $\mathbf{7}$ and 8 in comparison with 2 . The borderline metal ions $\mathrm{Co}(\mathrm{II}), \mathrm{Ni}$ (II), $\mathrm{Cu}$ (II) and $\mathrm{Zn}$ (II) are not extracted by these three ligands. In order to study the extraction of the thiophilic metal ions in more detail, single metal ion extraction experiments were carried out for $\mathrm{Ag}(\mathrm{I}), \mathrm{Hg}(\mathrm{II}), \mathrm{Cu}(\mathrm{I})$ and $\mathrm{Cu}(\mathrm{II})$ with the benzothiaoxacrown ligands 1-6 (Figure 2). Under changed experimental conditions - picrate was used in place of perchlorate as the counter ion and chloroform instead of nitrobenzene as the diluent - again a strong preference of $\operatorname{Ag}(\mathrm{I})$ was observed, whereas only a low extraction of $\mathrm{Cu}(\mathrm{I})$ and $\mathrm{Hg}(\mathrm{II})$ has been detected. In agreement with the competitive extraction experiment $\mathrm{Cu}(\mathrm{II})$ was not extracted. The thiaoxacrowns 2-5 with 5, 6 or 7 donor atoms and at least 2 sulfur atoms give nearly a quantitative extraction of $\operatorname{Ag}(\mathrm{I})(99 \%)$. In the case of ligand 1 the lower extraction (84\%) is possibly attributed to the poor size match between the small cavity $\left(\mathrm{d}_{(12-\text {-crown-4) }} \leq 1.5 \AA\right)$ [8] of this ligand with the $\mathrm{O}_{2} \mathrm{~S}_{2}$ donor set and the large $\mathrm{Ag}(\mathrm{I})$ ion $\left(\mathrm{d}_{\mathrm{Ag}(\mathrm{I})}=2.04 \AA\right)$ [32]. 

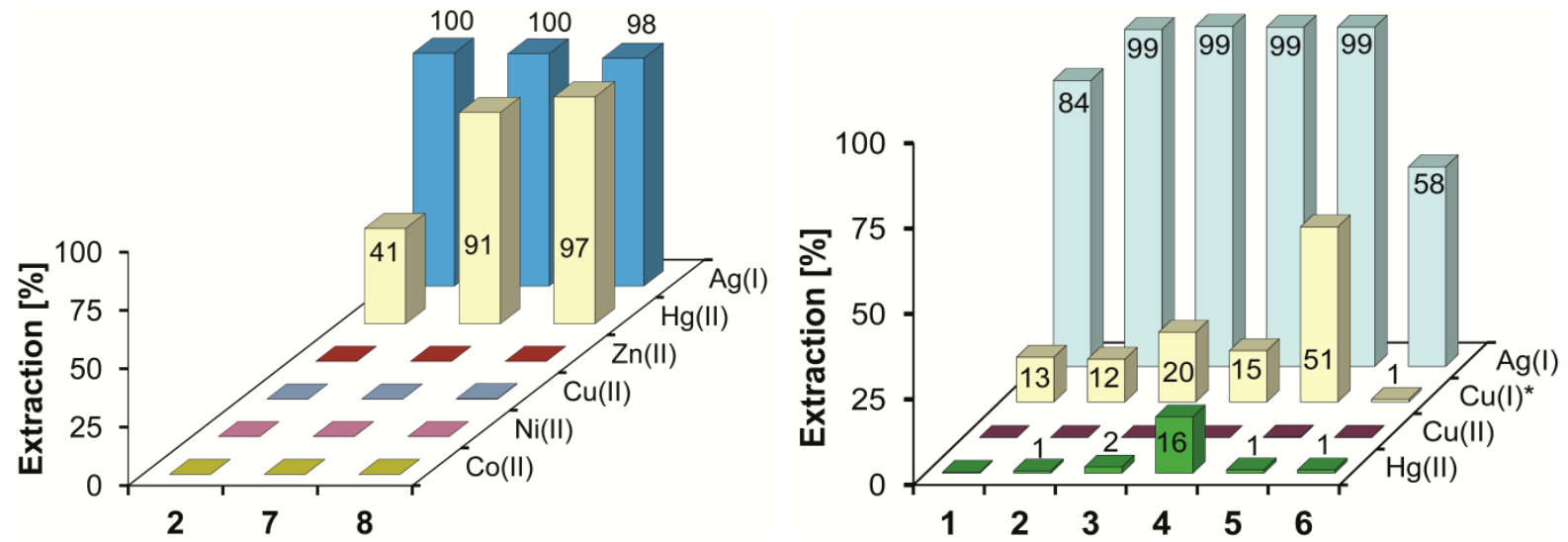

Figure 1. Competitive extraction of $\mathrm{Co}(\mathrm{II}), \mathrm{Ni}(\mathrm{II})$, Figure 2. Extraction of $\mathrm{Ag}(\mathrm{I}), \mathrm{Cu}(\mathrm{I}), \mathrm{Cu}(\mathrm{II})$ and $\mathrm{Cu}(\mathrm{II}), \mathrm{Zn}(\mathrm{II}), \mathrm{Hg}(\mathrm{II})$ and $\mathrm{Ag}(\mathrm{I})$ with ligands $2,7 \quad \mathrm{Hg}(\mathrm{II})$ with ligands 1-6; [ $\left.\mathrm{M}^{\mathrm{n}+}\right]=1 \times 10^{-4} \mathrm{M}$, [HPic] and 8; $\left[\mathrm{M}^{\mathrm{n}+}\right]=2 \times 10^{-4} \mathrm{M},\left[\mathrm{HClO}_{4}\right]=5 \times 10^{-3} \mathrm{M} ;=5 \times 10^{-3} \mathrm{M} ;[$ ligand $]=1 \times 10^{-3} \mathrm{M}$ in $\mathrm{CHCl}_{3}$; [ligand $]=5 \times 10^{-4} \mathrm{M}$ in nitrobenzene.

$*[$ ascorbic acid $]=1 \times 10^{-2} \mathrm{M}$ as reducing agent for $\mathrm{Cu}(\mathrm{II})$.

In this context it should be pointed out that $\mathrm{Ag}(\mathrm{I})$ frequently forms exocyclic complexes with thiacrowns [6, $10,17,24]$.

The significantly lower $\operatorname{Ag}(\mathrm{I})$ extraction with $6(58 \%)$ is most likely due to the presence of only one sulfur donor atom in this ligand. This ligand (6) gives also the lowest $\mathrm{Cu}(\mathrm{I})$ extraction. In comparison the extraction of $\mathrm{Cu}(\mathrm{I})$ with 1-4 falls in the range $12-20 \%$. The highest $\mathrm{Cu}(\mathrm{I})$ extraction of $51 \%$ was achieved with $\mathbf{5}$, which contains the largest number of sulfur donor atoms (4 S-donor atoms). Under the conditions employed, the extraction of $\mathrm{Hg}(\mathrm{II})$ is generally low. The highest extraction (16\%) was obtained with ligand 4, which has the largest ring size. In spite of the similar thiophilic character and size of $\mathrm{Hg}(\mathrm{II})$ and $\mathrm{Ag}(\mathrm{I})-$ $\mathrm{d}_{\mathrm{Hg}(\mathrm{II})}=2.06 \AA$ and $\mathrm{d}_{\mathrm{Ag}(\mathrm{I})}=2.04 \AA$ ) [32] - this result for $\mathrm{Hg}(\mathrm{II})$ is quite unexpected and especially different to the competitive experiment (see Figure 1). However, the single ion experiments were performed using $\mathrm{Hg}$ (II) in the form of $\mathrm{HgCl}_{2}$, which is only a slightly dissociated species and can hamper the phase transfer.

Comparable experiments with $\mathrm{Hg}\left(\mathrm{ClO}_{4}\right)_{2}$ as the mercury source in the aqueous phase and nitrobenzene as the organic diluent support this interpretation (Figure 3). Under these experimental conditions the extraction of $\mathrm{Hg}$ (II) by 1-6 achieves in all cases more than $50 \%$. The increasing extraction of $\mathrm{Hg}$ (II) follows the order $\mathbf{2}(55 \%)<\mathbf{3}(60 \%)<\mathbf{4}(76 \%)<\mathbf{6}(80 \%)<\mathbf{5}(83 \%)<\mathbf{1}(94 \%)$. For the ligands $\mathbf{1 - 5}$ this order is in agreement with the order of respective stability constants determined polarographically in acetonitrile (Table 1). 


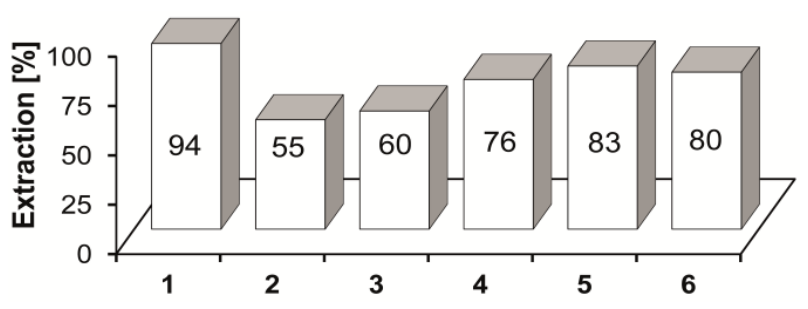

Figure 3. Extraction of $\mathrm{Hg}(\mathrm{II})$ by ligands 1-6; $\left[\mathrm{Hg}\left(\mathrm{ClO}_{4}\right)_{2}\right]=4 \times 10^{-4} \mathrm{M},\left[\mathrm{HClO}_{4}\right]=5 \times 10^{-3} \mathrm{M}$; [ligand] $=5 \times 10^{-4} \mathrm{M}$ in nitrobenzene.
Table 1. Stability constants of $[\mathrm{HgL}]^{2+}$ and $\left[\mathrm{HgL}_{2}\right]^{2+}$ complexes with ligands 1-6.

\begin{tabular}{cl}
\hline Ligand & $\log K$ \\
\hline $\mathbf{1}$ & $22.7^{a, b}$ \\
$\mathbf{2}$ & $18.0^{a}$ \\
$\mathbf{3}$ & $19.5^{a}$ \\
$\mathbf{4}$ & 20.1 \\
$\mathbf{5}$ & 21.0 \\
$\mathbf{6}$ & $14.7^{b}$ \\
\hline
\end{tabular}

$\log \mathrm{K}$ values were determined polarographically in $\mathrm{MeCN}\left(0.01 \mathrm{M} \mathrm{Et}_{4} \mathrm{NClO}_{4}\right)$ at $20{ }^{\circ} \mathrm{C}$; ${ }^{a}$ data from ref. [27]; ${ }^{b}$ data for $\left[\mathrm{HgL}_{2}\right]^{2+}$.

Figure 4 shows that $\operatorname{Ag}(\mathrm{I})$ extraction with the ligands 2-5 clearly depends on the counter ion. According to the Hofmeister series the hydrophobic picrate anion favors the extraction in comparison with the more hydrophilic nitrate. It is interesting to note, that $\operatorname{Ag}(\mathrm{I})$ extraction with ligands $\mathbf{2 - 5}$ from nitrate medium is significantly graded in the order $\mathbf{2}(18 \%)<\mathbf{5}(31 \%)<\mathbf{4}(57 \%)<\mathbf{3}(82 \%)$. This result is quite different in comparison with the $\mathrm{Hg}$ (II) extraction from perchlorate solution (see Figure 3) and a clear indication of the subtle differences in the extraction behavior of both soft metal ions. For a better understanding of the underlying reasons further studies are necessary with a focus on structural and binding aspects.

The composition of the extracted metal complexes in the organic phase can be determined by slope analysis of the extraction data in a $\log \mathrm{D}_{\mathrm{M}}-\log \mathrm{c}_{\mathrm{L}(\mathrm{org})}$ diagram [31]. The results for $\mathrm{Ag}(\mathrm{I})$ with 1-6 using $\mathrm{CHCl}_{3}$ as the diluent show linear relationships in each case (Figure 5). Nitrate was chosen as the counter ion for ligands $\mathbf{2 - 5}$ and in the case of ligands $\mathbf{1}$ and $\mathbf{6}$ picrate was used, in order to keep the $\mathrm{Ag}(\mathrm{I})$ extraction in a suitable range for this determination.

A slope of approximately one in a $\log \mathrm{D}_{\mathrm{Ag}}-\log \mathrm{c}_{\mathrm{L}(\text { org) }}$ diagram for $\mathrm{Ag}(\mathrm{I})$ extraction with 6 having an $\mathrm{O}_{4} \mathrm{~S}$ donor set indicates that 1:1 (M:L) complex species dominate in the organic phase (Figure 5). In contrast the slope of 1.7 for the $\operatorname{Ag}(\mathrm{I})$ extraction by $\mathbf{1}$ is in accordance with the formation of both 1:1 and 1:2 (M:L) complex species. The latter is the smallest crown of the series preferring obviously 1:2 sandwich $\left(\left[\mathrm{Ag} \mathbf{L}_{2}\right]^{+}\right)$arrangements. The ligands $\mathbf{2 - 5}$ show significantly smaller slopes between 0.2 and $0.6(\mathbf{3}: 0.2 ; \mathbf{2}$ : 0.3; 4: 0.4 and 5: 0.6) which excludes any meaningful conclusion about the speciation. 


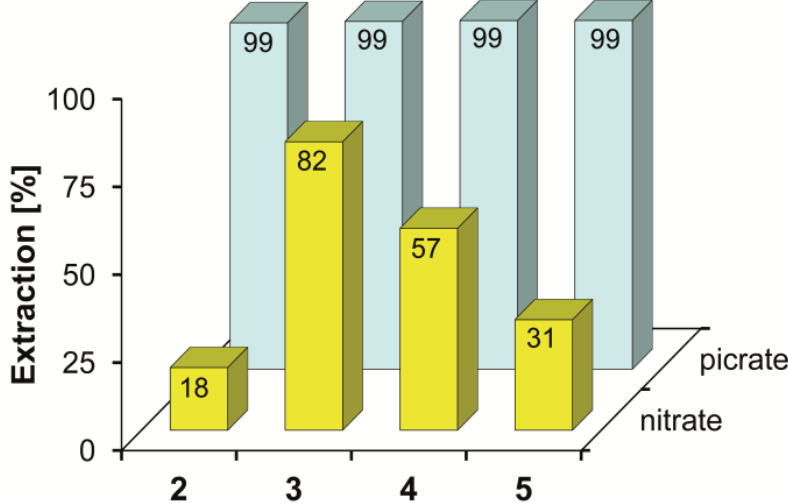

Figure 4. Dependence of the extraction of $\mathrm{Ag}(\mathrm{I})$ with $2-5$ on the counter ion; $\left[\mathrm{AgNO}_{3}\right]=1 \times 10^{-4} \mathrm{M}$; $\left[\mathrm{NaNO}_{3}\right]=1 \times 10^{-1} \mathrm{M}$ or $[\mathrm{HPic}]=5 \times 10^{-3} \mathrm{M}$; [ligand] $=1 \times 10^{-3} \mathrm{M}$ in $\mathrm{CHCl}_{3}$.

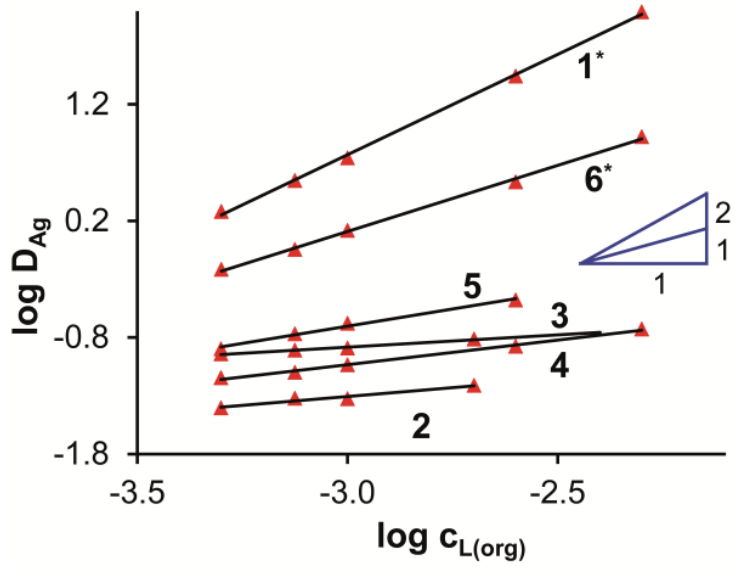

Figure 5. Dependence of the extraction of $\mathrm{Ag}(\mathrm{I})$ by 1-6 on ligand concentration; $\left[\mathrm{AgNO}_{3}\right]=1 \times 10$ ${ }^{4} \mathrm{M},\left[\mathrm{HNO}_{3}\right]=5 \times 10^{-4} \mathrm{M}$, $*[\mathrm{HPic}]=5 \times 10^{-3} \mathrm{M}$; [ligand] $=5 \times 10^{-4}-5 \times 10^{-3} \mathrm{M}$ in $\mathrm{CHCl}_{3}$ (slopes: $\mathbf{1}$ $1.7 ; 20.3 ; 30.2 ; 40.4 ; 5$ 0.6; 6 1.1).

To obtain some further evidence in respect of the composition of the formed $\operatorname{Ag}(\mathrm{I})$ complexes, a comparative ESI-MS analysis of complex composition in the organic phase was undertaken. For this purpose the ligands were dissolved in chloroform and mixed in the ratio of 1:1 with a solution of $\mathrm{CF}_{3} \mathrm{SO}_{3} \mathrm{Ag}$ in acetone. The resulting ESI-MS spectra are shown in Figure 6.

For ligand 1, the smallest macrocycle with an $\mathrm{O}_{2} \mathrm{~S}_{2}$ donor set, the complex cations $\left[\right.$ Ag. 1] ${ }^{+}(\mathrm{m} / \mathrm{z}$ 392.9) and $\left[\mathrm{Ag} \cdot(\mathbf{1})_{2}\right]^{+}(\mathrm{m} / \mathrm{z}$ 674.5) can be detected in the chloroform/acetone solution. The larger macrocycles $\mathbf{2}, \mathbf{3}, \mathbf{4}$ and $\mathbf{5}$, each with 5, 6 or 7 donor atoms, show the formation of 1:1 complexes as only a signal for the respective $1: 1$ species $[\mathrm{AgL}]^{+}$has been found in the individual spectra. In the case of ligand $\mathbf{5}$ the major signal at $\mathrm{m} / \mathrm{z} 452.9$ is connected with the loss of a thioethylene group through fragmentation during the excitation process. However, the second largest signal at m/z 513.0 indicates the presence of the 1:1 species. For 6, which contains an $\mathrm{O}_{4} \mathrm{~S}$ donor set, besides the $[\mathrm{AgL}]^{+}$species, the species $\left[\mathrm{Ag} \mathbf{L}_{2}\right]^{+}$is also detected. This is in contrast to the extraction data (see Figure 5) where only 1:1 species have been detected. In spite of the different experimental conditions for extraction and ESI-MS experiments, the results are in good agreement for the observed complex compositions and confirm the interpretation. 

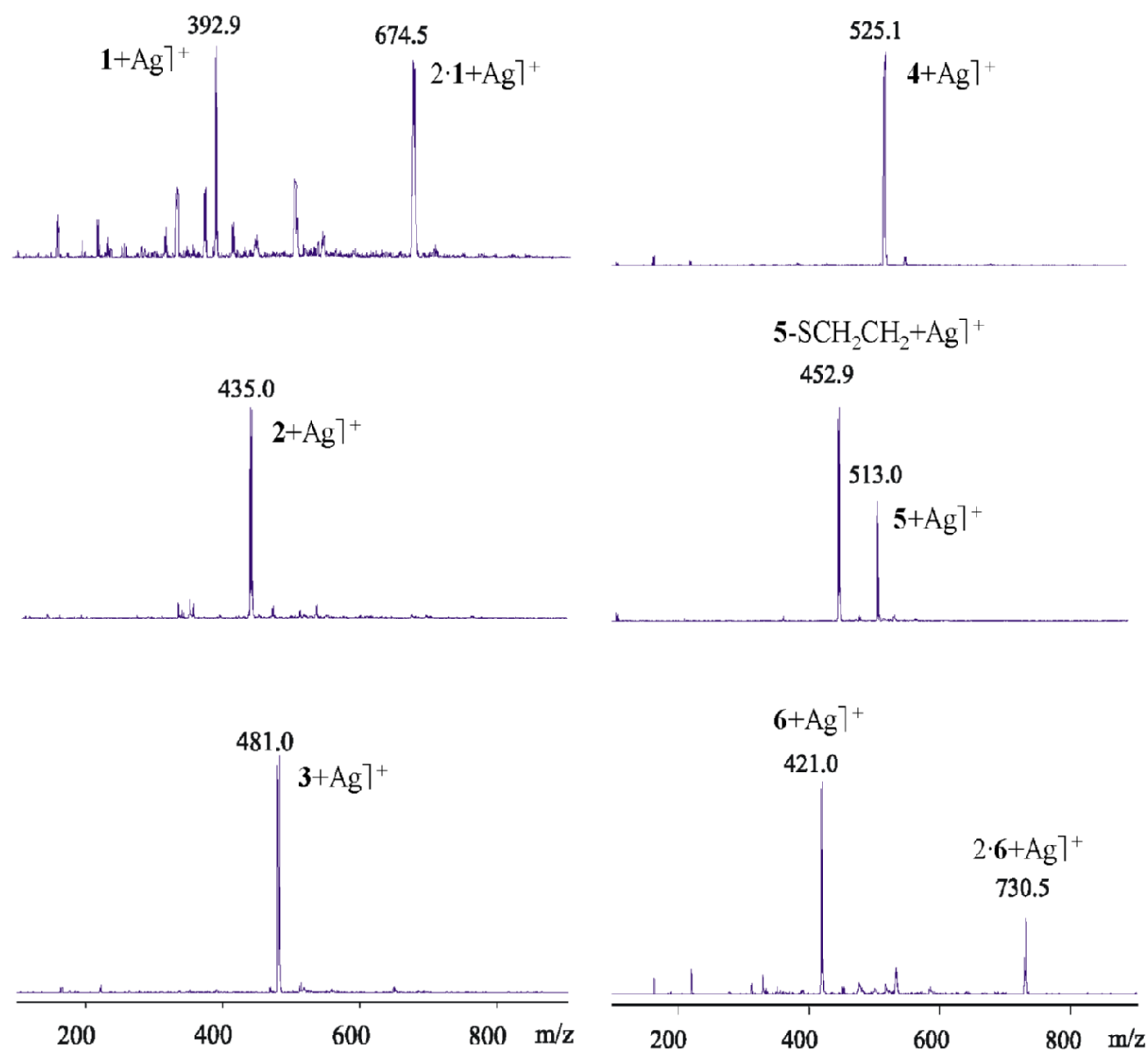

Figure 6. ESI-MS spectra for equimolar mixtures $\left(0.5 \mathrm{~mL}\right.$ each) of a solution of 1-6 $(5 \mathrm{mM})$ in $\mathrm{CHCl}_{3}$ and of $\mathrm{CF}_{3} \mathrm{SO}_{3} \mathrm{Ag}(5 \mathrm{mM})$ in acetone.

One important influencing factor on the extraction equilibria is the nature of the organic diluent employed. In general, nitrobenzene very often enhances the extraction ability of a ligand due to strong solvation effects for the extracted compound. For comparison, $\operatorname{Ag}(\mathrm{I})$ extraction experiments were carried out with 2 and 7 both in 1,2-dichloroethane (DCE) or nitrobenzene (NB). As shown in Figure 7, the expected extraction enhancement for nitrobenzene was observed only in case of $\mathbf{2}$ pointing to a favored solvation of the extracted complex. In the case of $\mathbf{7}$, the presence of the lipophilic benzothiazolium substituent may compensate this effect. $\mathrm{Ag}(\mathrm{I})$ extraction is comparable in both solvents, $78 \%(1,2-$ dichloroethane) and 75\% (nitrobenzene), respectively. 


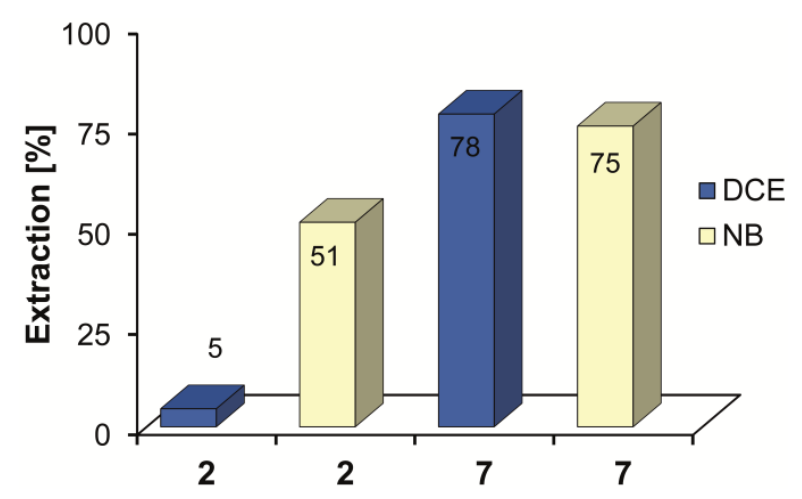

Figure 7. Influence of the diluent on the extraction of $\mathrm{Ag}(\mathrm{I})$ by 2 and $7 ;\left[\mathrm{AgNO}_{3}\right]=1 \times 10^{-4} \mathrm{M},\left[\mathrm{HNO}_{3}\right]=$ $5 \times 10^{-4} \mathrm{M}$; [ligand] $=1 \times 10^{-3} \mathrm{M}$ in DCE and NB.

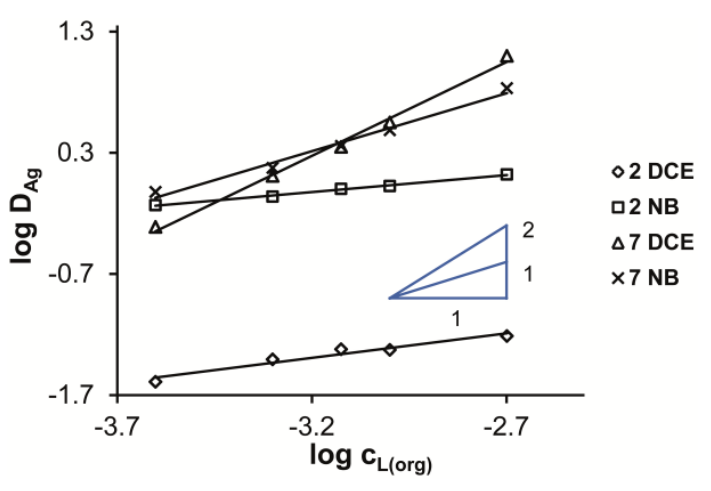

Figure 8. Dependence of the extraction of $\mathrm{Ag}(\mathrm{I})$ with 2 and 7 on ligand concentration; $\left[\mathrm{AgNO}_{3}\right]=1 \times 10^{-4} \mathrm{M},\left[\mathrm{HNO}_{3}\right]=5 \times 10^{-4} \mathrm{M}$; [ligand] $=2.5 \times 10^{-4}-2 \times 10^{-3} \mathrm{M}$ in DCE and $\mathrm{NB} ; \quad$ slopes for $20.3(\mathrm{NB})$ and 0.4 (DCE); for $71.0(\mathrm{NB})$ and $1.6(\mathrm{DCE})$.

However, a change of the organic diluent can also have a significant influence on the composition of the extracted $\operatorname{Ag}(\mathrm{I})$ complex. Slope analyses employing a $\log \mathrm{D}_{\mathrm{Ag}}-\log \mathrm{c}_{\mathrm{L}(\mathrm{org})}$ diagram for $\mathrm{Ag}(\mathrm{I})$ extraction with $\mathbf{2}$ and $\mathbf{7}$ for 1,2-dichloroethane or nitrobenzene diluents are shown in Figure 8. Thus, for $\mathbf{7}$ both [AgL $]^{+}$ and $\left[\mathrm{AgL}_{2}\right]^{+}$species are formed in 1,2-dichloroethane (slope 1.6), whereas only a $[\mathrm{AgL}]^{+}$species is formed in nitrobenzene (slope 1.0) exclusively. In comparison, experiments for $\mathbf{2}$ gave very low slopes of 0.3 and 0.4 in 1,2-dichloroethane and nitrobenzene, respectively, and are in agreement with the result obtained when chloroform was used as the diluent (see Figure 5). Obviously, the high water solubility of the $\operatorname{Ag}(\mathrm{I})$ complex of $\mathbf{2}$ (see below) prevents a clear indication of the composition of the extracted species.

In order to probe the assumption that the extracted $\mathrm{Ag}(\mathrm{I})$ complex species of the ligands $\mathbf{2}, \mathbf{3}$ and $\mathbf{5}$ possess an enhanced water solubility, UV-Vis spectroscopic analysis of both aqueous and organic phases were carried out after extraction. The results are shown in Figures 9 and 10. In the absence of $\operatorname{Ag}(\mathrm{I})$ no characteristic UV absorption could be observed in the aqueous phase. In contrast, after extraction, two absorption bands at $275 \mathrm{~nm}$ and $303 \mathrm{~nm}$ appear in both phases and indicate similar $\mathrm{Ag}(\mathrm{I})$ complexes (Figure 9 and 10). This observation supports the assumption that $\mathrm{Ag}(\mathrm{I})$ complexation results in a significant solubility increase of the $\operatorname{Ag}(\mathrm{I})$ species in the aqueous phase. Furthermore, the increase of the characteristic absorbance in the aqueous phase in the order $\mathbf{5}<\mathbf{2}<\mathbf{3}$ correlates with the observed decreasing slopes in the corresponding analyses obtained for the respective extraction experiments (Figure 5). In agreement with this tendency, the absorbance of both characteristic UV bands of the extracted $\mathrm{Ag}(\mathrm{I})$ complexes in the organic phase increase in the order $\mathbf{3}<\mathbf{2}<\mathbf{5}$ (Figure 10) which is the opposite trend to the absorbance in the aqueous phase. 


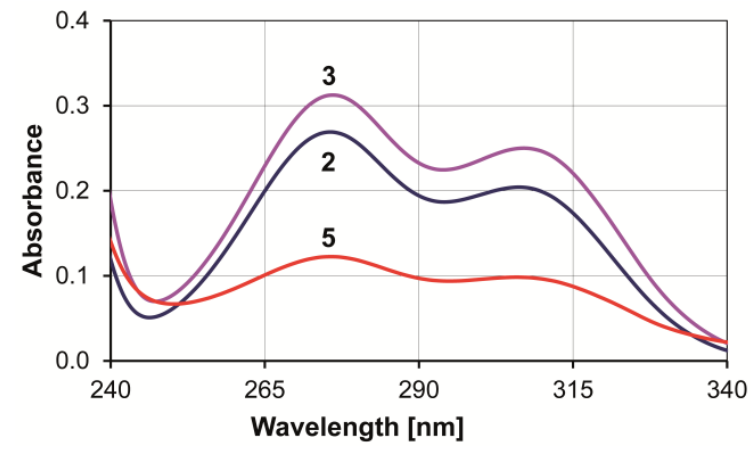

Figure 9. UV-Vis spectra of the aqueous phase after extraction of $\mathrm{Ag}(\mathrm{I})$ with 2, 3 and 5; for $\mathbf{3}$ and $5\left[\mathrm{AgNO}_{3}\right]=5 \times 10^{-4} \mathrm{M},\left[\mathrm{HNO}_{3}\right]=5 \times 10^{-3} \mathrm{M}$; for 2 $\left[\mathrm{AgClO}_{4}\right]=5 \times 10^{-4} \mathrm{M}$; [ligand] $=5 \times 10^{-4} \mathrm{M}$ in 1,2-dichloroethane.

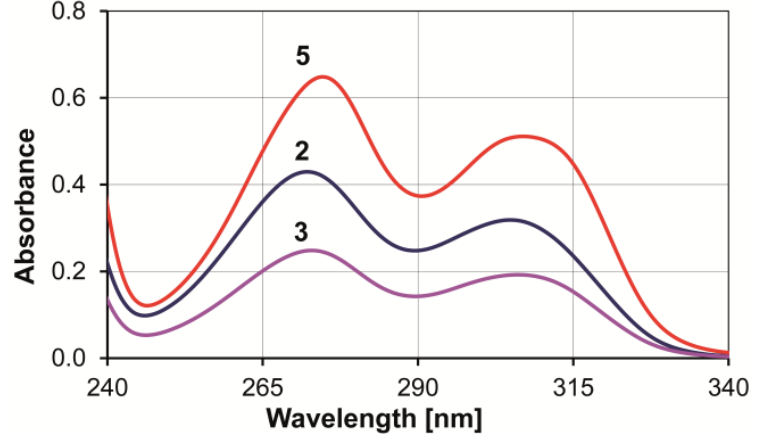

Figure 10. UV-Vis spectra of the organic phase after extraction of $\mathrm{Ag}(\mathrm{I})$ with 2, 3 and 5; for $\mathbf{3}$ and $\mathbf{5}$ $\left[\mathrm{AgNO}_{3}\right]=5 \times 10^{-4} \mathrm{M},\left[\mathrm{HNO}_{3}\right]=5 \times 10^{-3} \mathrm{M}$; for 2 $\left[\mathrm{AgClO}_{4}\right]=5 \times 10^{-4} \mathrm{M}$; [ligand] $=5 \times 10^{-4} \mathrm{M}$ in 1,2-dichloroethane.

\section{Conclusions}

The novel benzothiaoxacrown compounds 1-8 show a good extraction ability toward the soft metal ions $\mathrm{Ag}(\mathrm{I})$ and $\mathrm{Hg}(\mathrm{II})$ in both single and competitive metal ion experiments with a preferred extraction of $\operatorname{Ag}(\mathrm{I})$. In contrast, the extraction of the soft $\mathrm{Cu}(\mathrm{I})$ ion with these ligands is weak; the metal ions $\mathrm{Co}(\mathrm{II})$, $\mathrm{Ni}(\mathrm{II}), \mathrm{Cu}(\mathrm{II})$ and $\mathrm{Zn}(\mathrm{II})$ are not extracted at all. It is interesting to note that, in comparison with $\mathrm{Ag}(\mathrm{I})$, the extraction behavior of $\mathrm{Hg}$ (II) with the ligands studied is more sensitive toward the chosen experimental conditions. This concerns especially the choice of the organic diluent and the counter ion in the aqueous phase. The highest $\mathrm{Hg}(\mathrm{II})$ extraction was obtained with ligands 1, 7 and $\mathbf{8}$ using nitrobenzene as the diluent and perchlorate as the anion.

For $\operatorname{Ag}(\mathrm{I})$ the complex composition in the organic phase varies between 1:2 and 1:1 (M:L) depending on the ring size. This result correlates with the degree of size match between the metal ion and the macrocyclic ring and is in agreement with literature data for relevant complexes [10,15,27,28], suggesting the formation of 1:2 sandwich or 1:2 linear complexes and 1:1 (in or above the macrocyclic ring) structure arrangements with different coordination numbers (Scheme 2). This observation reflects the known variation of the $\operatorname{Ag}(\mathrm{I})$ coordination number - with a preference between 2 and 6 - depending on the ligand used $[24,33]$.

Scheme 2 .

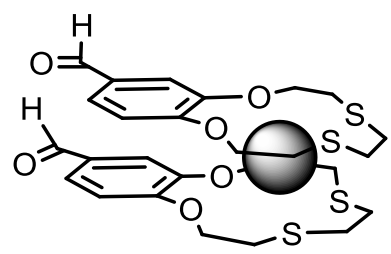<smiles>O=Cc1ccc2c(c1)OCCOCCS1(CCOCCOCCO1)c1ccc(C=O)cc1OCCOCCSCCOCCO2</smiles><smiles>O=Cc1ccc2c(c1)OCCSCCOCCSCCO2</smiles>

Of interest is the fact that the lipophilicity of the benzothiaoxocrowns $\mathbf{2}, \mathbf{3}$ and $\mathbf{5}$ decreases upon extraction. UV-Vis measurements reveal that these ligands are exclusively in the organic phase prior to extraction. Afterwards the relevant complexes show a relatively high solubility in water. 


\section{Acknowledgments}

The research was supported by INTAS program 2001-0267. MW thanks Massey University for a postdoctoral fellowship.

\section{References}

1) Solvent Extraction Principles and Practice, J. Rydberg, M. Cox, C. Musikas, G.R. Choppin, Eds., Marcel Dekker, NewYork, 2004.

2) A.M. Wilson, P.J. Bailey, P.A. Tasker, J.R. Turkington, R.A. Grant, J.B. Love, Chem. Soc. Rev., 43, 123-134 (2014).

3) R.M. Izatt, S.R. Izatt, R.L. Bruening, N.E. Izatt, B.A. Moyer, Chem. Soc. Rev., 43, 2451-2475 (2014).

4) Macrocyclic Compounds in Analytical Chemistry, Y.A. Zolotov, Ed., Wiley, NewYork, 1997.

5) Macrocyclic Chemistry: Current Trends and Future Perspectives, K. Gloe. Ed., Springer, Dordrecht, 2005.

6) D. Sevdic, H. Meider, J. Inorg. Nucl. Chem., 39, 1409-1413 (1977).

7) D. Sevdic, L. Fekete, H. Meider, J. Inorg. Nucl. Chem., 42, 885-889 (1980).

8) I.M. Kolthoff, Anal. Chem., 51, 1-22 (1979).

9) K. Saito, Y. Masuda, E. Sekido, Anal. Chim. Acta, 151, 447-455 (1983).

10) E. Sekido, K. Saito, Y. Naganuma, H. Kumazaki, Anal. Sci., 1, 363-368 (1985).

11) E. Sekido, K. Chayama, M. Muroi, Talanta, 32, 797-802 (1985).

12) M. Muroi, A. Hamaguchi, E. Sekido, Anal. Sci., 2, 351-356 (1986).

13) M. Oue, K. Kimura, T. Shono, Anal. Chim. Acta, 194, $293-298$ (1987).

14) W.J. McDowell, Sep. Sci. Technol., 23, 1251-1268 (1988).

15) A.J. Blake, M. Schröder, Adv. Inorg. Chem., 35, 1-80 (1990).

16) G. Wu, W. Jiang, J.D. Lamb, J.S. Bradshaw, R.M. Izatt, J. Am. Chem. Soc., 113, 6538-6541 (1991).

17) S. Kim, L.F. Lindoy, S.S. Lee, Coord. Chem. Rev., 280, 176-202 (2014).

18) K. Gloe. P. Mühl, L. Beyer, M. Mühlstädt, E. Hoyer, Solvent Extr. Ion Exch., 4, 907-925 (1986).

19) K. Gloe, P. Mühl, J. Beger, Z. Chem., 28, 1-14 (1988).

20) F. Dietze, K. Gloe, R. Jacobi, P. Mühl. J. Beger, M. Petrich, L. Beyer, E. Hoyer, Solvent Extr. Ion Exch., 7, 223-247 (1989).

21) M.C. Aragoni, M. Arca, A. Bencini, S. Biagini, A.J. Blake, C. Caltagirone, F. Demartin, G. De Filippo, F.A. Devillanova, A. Garau, K. Gloe, F. Isaia, V. Lippolis, B. Valtancoli, M. Wenzel, Inorg. Chem., 47, 8391-8404 (2008).

22) O. Heitzsch, K. Gloe, H. Stephan, E. Weber, Solvent Extr. Ion Exch., 12, 475-496 (1994).

23) K. Gloe, T. Krüger, H. Stephan, M. Wagner, U. Drutkowski, R.-M. Olk, U. Leckelt, R. Richter, E. Hoyer, Z. Anorg. Allg. Chem., 624, 152-158 (1998).

24) T. Rambusch, K. Gloe, K. Gloe, J. Prakt. Chem., 341, 202-217 (1999).

25) M.V. Alfimov, A.I. Vedernikov, S.P. Gromov, Y.V. Fedorov, O.A. Fedorova, Russ. Chem. Bull., 46, 967-974 (1997).

26) O.A. Fedorova, A.I. Vedernikov, O.V. Yescheulova, Y.V. Pershina, P.V. Tsapenko, S.P. Gromov, Synthetic Commun., 32, 1909-1915 (2002). 
27) O.A. Fedorova, Y.V. Fedorov, A.I. Vedernikov, S.P. Gromov, O.V. Yescheulova, M.V. Alfimov, M. Woerner, S. Bossmann, A. Braun, J. Saltiel, J. Phys. Chem. A, 106, 6213-6222 (2002).

28) L.G. Kuzmina, A.I. Vedernikov, S.N. Dmitrieva, J.A.K. Howard, S.P. Gromov, Russ. Chem. Bull., 56, 1003-1012 (2007).

29) A.I. Vedernikov, L.G. Kuzmina, Y.A. Strelenko, J.A.K. Howard, S.P. Gromov, Russ. Chem. Bull., 59, 927-940 (2010).

30) S.N. Dimitrieva, N.I. Sidorenko, N.A. Kurchavov, A.I. Vedernikov, A.Y. Freidzon, L.G. Kuzmina, A.K. Buryak, T.M. Buslaeva, A.A. Bagaturyants, Y.A. Strelenko, J.A.K. Howard, S.P. Gromov, Inorg. Chem., 50, 7500-7510 (2011).

31) H. Stephan, M. Kubeil, K. Gloe, K. Gloe, in Analytical Methods in Supramolecular Chemistry, Ch. Schalley, Ed., Wiley-VCH, Weinheim, pp. 105-127, 2012.

32) Y. Marcus, Chem. Rev., 88, 1475-1498 (1988).

33) B. Antonioli, D.J. Bray, J.K. Clegg, K. Gloe, K. Gloe, O. Kataeva, L.F. Lindoy, J.C. McMurtrie, P.J. Steel, C.J. Sumby, M. Wenzel, Dalton Trans., 4783-4794 (2006). 